\title{
Effect of dutasteride on clinical progression of benign prostatic hyperplasia in asymptomatic men with enlarged prostate: a post hoc analysis of the REDUCE study \\ (c) (1) (8)
}

\section{Paul Toren uro-oncology fellow, David Margel uro-oncology fellow, Girish Kulkarni assistant professor, Antonio Finelli associate professor, Alexandre Zlotta professor, Neil Fleshner professor}

Division of Urology, Department of Surgery, University of Toronto, University Health Network, 610 University Avenue, 3-130, Toronto, Ontario, Canada M5G 2M9

\begin{abstract}
Objective To assess the role of dutasteride in preventing clinical progression of benign prostatic hyperplasia in asymptomatic men with larger prostates.

Design Post hoc analysis of four year, double blind Reduction by Dutasteride of Prostate Cancer Events (REDUCE) study

Participants 1617 men randomised to dutasteride or placebo with a prostate size $>40 \mathrm{~mL}$ and baseline International Prostate Symptom Score (IPSS) <8. Subjects who took medications for benign prostatic hyperplasia were excluded at study entry.

Interventions Placebo or dutasteride $0.5 \mathrm{mg}$ daily.

Main outcome measures Comparison of risk of clinical progression of benign prostatic hyperplasia at four years (defined as $a \geq 4$ point worsening on IPSS, acute urinary retention, urinary tract infection, or surgery related to benign prostatic hyperplasia).

Results 825 participants took placebo, 792 took dutasteride. A total of 464 (29\%) experienced clinical progression benign prostatic hyperplasia, 297(36\%) taking placebo, $167(21 \%)$ taking dutasteride $(\mathrm{P}<0.001)$. The relative risk reduction was $41 \%$ and the absolute risk reduction $15 \%$, with a number needed to treat (NNT) of 7 . Among men who had acute urinary retention and surgery related to benign prostatic hyperplasia, the absolute risk reduction for dutasteride was $6.0 \%$ and $3.8 \%$, respectively. On multivariable regression analysis adjusting for covariates, dutasteride significantly reduced clinical progression of benign prostatic hyperplasia with an odds ratio of 0.47 (95\% $\mathrm{Cl} 0.37$ to $0.59, \mathrm{P}<0.001)$. Analysis of time to first event yielded a hazard ratio of $0.673(P<0.001)$ for those taking dutasteride. Sexual adverse events were most common and similar to prior reports.
\end{abstract}

Limitations Further prospective studies may be warranted to demonstrate generalisability of these results.

Conclusions This study is the first to explore the benefit of treating asymptomatic or mildly symptomatic men with an enlarged prostate.
Dutasteride significantly decreased the incidence of benign prostatic hyperplasia clinical progression.

\section{Introduction}

Benign prostatic hyperplasia commonly causes lower urinary tract symptoms among men as they age. ${ }^{1}$ The treatment of this progressive condition is often adjusted for prostate size. Progression of prostatic hyperplasia is defined as an aggregate measure of worsening lower urinary tract symptoms, acute urinary retention, and need for prostate surgery. Pivotal phase III trials such as Medical Therapy of Prostatic Symptoms (MTOPS) and Combination of Avodart and tamsulosin $(\mathrm{ComBAT})^{23}$ showed that combination medical therapy with a $5 \alpha$ reductase inhibitor and $\alpha$ blocker can halt the progression of benign prostatic hyperplasia among men with moderate to severe lower urinary tract symptoms, with the greatest benefit noted in men with enlarged prostates. An important aspect of both of these trials, as well as other studies showing the preventive benefits of $5 \alpha$ reductase inhibitors, ${ }^{4}$ is that they have excluded men with mild lower urinary tract symptoms at screening (MTOPS excluded International Prostate Severity Scale (IPSS) scores $<8$; ComBAT excluded IPSS scores $<12$ ). ${ }^{25}$ Population data on the natural course of benign prostatic hyperplasia from Olmstead County indicate that average prostate size grows at an exponential rate of $1.6 \%$ per year. ${ }^{1}$ While the rate was not affected by age, it was higher in men with larger prostates. The unadjusted and adjusted relative risk of medical or surgical treatment for prostate volumes $>30 \mathrm{~mL}$ were 4.2 (95\% confidence interval 2.2 to 8.2 ) and 2.3 (1.1 to 4.7 ) respectively, ${ }^{1}$ while the unadjusted relative risk of acute urinary retention for prostate size $>30 \mathrm{~mL}$ was 3.0 (1.0 to 9.0). These data were derived from both asymptomatic and symptomatic men. A prior meta-analysis suggested that, as well as predicting 
outcomes, a prostate size $>40 \mathrm{~mL}$ predicts a significant difference in the magnitude of improvement with a $5 \alpha$ reductase inhibitor compared with placebo. ${ }^{6}$ A prostate size $>40 \mathrm{~mL}$ is also the volume used to define prostatic enlargement in the recent European Association of Urology guidelines on benign prostatic hyperplasia.?

The choice of treatment for symptomatic patients is often based on prostate size: $\alpha$ blocker monotherapy for patients with small prostates and combination therapy of $5 \alpha$ reductase inhibitors plus $\alpha$ blockers for patients with enlarged prostates. Obviously, asymptomatic men with small prostates do not require any treatment. However, it is not uncommon in clinical practice to encounter men with enlarged prostates but minimal lower urinary tract symptoms. These men are identified because of digital rectal examination or transrectal ultrasound findings for men with elevated prostate specific antigen levels. Because these patients have not been included in pivotal trials of treatment for benign prostatic hyperplasia, both the risk of clinical progression and the potential benefit of preventive treatment with $5 \alpha$ reductase inhibitors are unknown. The Reduction by Dutasteride of Prostate Cancer Events (REDUCE) cancer prevention trial $^{8}$ is a large multinational prospective randomised study that measured prostate volume and urinary symptoms at baseline and included men with minimal or no lower urinary tract symptoms. We can therefore use this dataset to determine if there is any role for $5 \alpha$ reductase inhibitors in the treatment of asymptomatic men with enlarged prostates.

\section{Methods}

The REDUCE study was designed to assess the efficacy of dutasteride in decreasing the incidence of biopsy-detected prostate cancer over a four year period in men at increased risk of prostate cancer. Participants were randomised to placebo or dutasteride $0.5 \mathrm{mg}$ daily. Inclusion and exclusion criteria are described in the original publication. ${ }^{8}$ This secondary analysis was prompted by the uniqueness of this dataset to answer the relatively common scenario: "How should I manage an asymptomatic man with an enlarged prostate?" This analysis aims to assess the benefit of dutasteride in men with mild or no urinary symptoms and enlarged prostates to prevent clinical progression of benign prostatic hyperplasia. The population assessed in this study includes participants randomised to both trial arms who had an International Prostate Severity Scale (IPSS) score $<8$ and a prostate size $40-80 \mathrm{~mL}$ on initial transrectal ultrasound (men with a prostate size of $>80 \mathrm{~mL}$ were excluded from the original study). Subjects were excluded if they were taking any prostate related medications.

IPSS questionnaires were completed at baseline and at six-month intervals during the study. Urinary flow rates were measured at study entry (patients with a flow rate $<5 \mathrm{ml} / \mathrm{sec}$ were excluded from the study) and in selected centres during follow-up. Clinical events-including acute urinary retention, prostate surgery related to benign prostatic hyperplasia, and urinary tract infection-were reported on case report forms every six months, and adverse events were assessed every three months during the study. All episodes of acute urinary retention were documented along with their cause (such as related to benign prostatic hyperplasia). ${ }^{9}$

Similar to the major landmark trials ${ }^{23}$ and a Cochrane review, ${ }^{10}$ we used a composite index of clinical progression of benign prostatic hyperplasia as our primary end point. Participants who experienced urinary retention related to benign prostatic hyperplasia, surgery for benign prostatic hyperplasia, urinary tract infection, or symptom deterioration of IPSS score $\geq 4$ points during the study were considered to have clinically progressed. A change in IPSS score of $\geq 4$ has been shown to correspond to a change in patients' global feeling of urination which is clinically meaningful ${ }^{11}{ }^{12}$ and been used in several large trials of benign prostatic hyperplasia. ${ }^{23}{ }^{10} \mathrm{We}$ also assessed adverse events between groups.

\section{Statistical analyses}

Our power calculations-based on 792 experimental subjects and 825 control subjects, four years of follow-up, and prior data estimating median time to progression of about 14.9 years with placebo ${ }^{2}$-indicated we are able to detect true hazard ratios (relative risks) of placebo versus dutasteride groups of 0.859 or 1.168 with $80 \%$ power and $\alpha=0.05$.

Statistical analysis was performed using SAS version 9.2 (SAS Institute, Cary, NC, USA). Student's $t$ test and $\chi^{2}$ tests were used to compare groups. A multivariable logistic regression assessed the effect of dutasteride on clinical progression of benign prostatic hyperplasia adjusting for age and baseline variables (IPSS, prostate volume, post-void residual urine volume, and peak urinary flow rate). Further, we performed an analysis of time to first event. Symptomatic progression was defined as the time of the first of two consecutive measures of IPSS $\geq 4$ points from the baseline IPSS score (after randomisation). This was done to reduce variation based on only one questionnaire and demonstrate a durable change in symptoms. IPSS questionnaires were administered every six months during the four year study. Cox proportional hazard ratios were used to compare groups.

\section{Results}

Our study cohort consisted of 1617 men, 825 randomised to placebo, and 792 randomised to dutasteride. Table $1 \Downarrow$ shows baseline patient characteristics. The groups were balanced for age, prostate volume, and baseline flow parameters; there was no significant difference between groups.

A total of 464 patients (29\%) experienced clinical progression of benign prostatic hyperplasia: 297 (36\%) taking placebo, 167 ( $21 \%)$ taking dutasteride $(\mathrm{P}<0.001$ for difference). The relative risk reduction was $41 \%$ and absolute risk reduction was $15 \%$, with a number needed to treat of 6.7. Clinical events in each group are summarised in table $2 \Downarrow$. Seventy six patients $(4.7 \%)$ had acute urinary retention: 63 taking placebo and 13 taking dutasteride $(\mathrm{P}<0.001)$. Of the 46 patients who had surgery related to benign prostatic hyperplasia, 39 were taking placebo and seven were taking dutasteride $(\mathrm{P}<0.001)$. One hundred and forty one patients had a urinary tract infection: 87 were taking placebo and 54 taking dutasteride $(\mathrm{P}<0.001)$. Figure $1 \Downarrow$ shows absolute and relative risk reductions for each event and the composite end point. On multivariable logistic regression analysis, dutasteride was the only factor that significantly reduced clinical progression of benign prostatic hyperplasia, with an odds ratio of 0.47 (95\% confidence interval 0.37 to 0.59 , $\mathrm{P}<0.001)$. Excluding patients with a urinary tract infection from the composite end point yielded similar results, with an odds ratio of 0.428 ( 0.336 to $0.545, \mathrm{P}<0.001)$. The number of prostate cancers with a Gleason score $\geq 7$ was not significantly different between groups ( 16 for placebo, 12 for dutasteride) in our cohort.

In our time-to-event analysis, 426 patients had two consecutive International Prostate Severity Scale (IPSS) scores $\geq 4$ points greater than baseline score. Figure $2 \Downarrow$ shows the time to first event indicating progression of benign prostatic hyperplasia (acute urinary retention, surgery related to benign prostatic 
hyperplasia, urinary tract infection, or symptomatic progression) for both groups. The hazard ratio for clinical progression among those randomised to dutasteride was $0.673(\mathrm{P}<0.001)$ relative to placebo. Other significant predictors of reaching the composite end point were baseline prostate volume (hazard ratio 1.007, $\mathrm{P}=0.008$ ), baseline IPSS score (hazard ratio 0.958 , $\mathrm{P}=0.046$ ), and baseline urinary flow rate (hazard ratio 0.966 $\mathrm{P}<0.001)$.

The most common drug related side events were erectile dysfunction, at $5.1 \%$ and $9.0 \%(\mathrm{P}=0.02)$ in the placebo and dutasteride arms respectively, and decreased or no libido, at $2.3 \%$ and $6.8 \%(\mathrm{P}<0.001)$ in the two arms. Table $3 \Downarrow$ documents all adverse events that occurred with an incidence of $>1 \%$ in our study population.

\section{Discussion}

Medical management goals of benign prostatic hyperplasia mainly consist of alleviating urinary symptoms, but other goals of treatment include improving bladder emptying, decreasing the effects of bladder outlet obstruction, and preventing future events such as haematuria, retention, and need for surgery. To our knowledge, this is the first study to explore the preventive benefit of treating asymptomatic or mildly symptomatic men at risk of progression of benign prostatic hyperplasia. Previous trials, for practical and ethical reasons, have focused on men with moderate to severe lower urinary tract symptoms. ${ }^{235}$ Analysis of the placebo arm of some of these trials has demonstrated that an enlarged prostate is a marker for patients at risk for benign prostatic hyperplasia progression. ${ }^{2}{ }^{13}$ In these men with an enlarged prostate, $5 \alpha$ reductase inhibitors are recognised to be of greatest benefit. ${ }^{235}$ This study confirms the prophylactic benefit in asymptomatic or mildly symptomatic men, with the side effect profile as expected.

With men with no lower urinary tract symptoms enrolled, the REDUCE study data uniquely allowed us to demonstrate the benefit of a $5 \alpha$ reductase inhibitor in asymptomatic men at risk of benign prostatic hyperplasia progression due to prostatic enlargement. Careful monitoring and recording of events and causes of urinary retention, surgery, and urinary tract infections during this clinical trial provided accurate data for analysis. Although this is a post-hoc analysis, there are practical barriers to performing a prospective randomised trial in this population, including the need to perform a large number of transrectal ultrasound scans in asymptomatic men. The only other large dataset to our knowledge which contains data for similar patients does not contain routine information on prostate size. ${ }^{14}{ }^{15}$ Table $4 \Downarrow$ presents the number needed to treat (NNT) to allow physicians to gauge the preventive benefit to this subset of patients over four years.

\section{Study limitations}

Although we used data from a well executed randomised clinical trial, there are some limitations to the present study. The population of men at increased risk of prostate cancer in the REDUCE study may not be representative of the broader population. By selecting men with an IPSS score of $<8$, there may be some regression to the mean, resulting in higher scores over time. None the less, this statistical effect is balanced by the fact that changes on the IPSS score are considered more clinically important at lower baseline values. ${ }^{11}{ }^{12}$ The a priori cut-off value for prostate size that we used $(40 \mathrm{~mL})$ is higher than the value of $30 \mathrm{~mL}$ often used to categorise large prostates. However, both values are arbitrary, and we felt a cut-off of
$>40 \mathrm{~mL}$ was clinically more representative of larger prostates that would benefit from preventive therapy. ${ }^{7}$

\section{Comparison with other studies}

Other studies have noted that using $5 \alpha$ reductase inhibitors in men with enlarged prostates have a larger benefit in men who are more symptomatic. ${ }^{16}$ With the Proscar Long-Term Efficacy and Safety Study (PLESS) dataset, it was seen that the relative risk reduction in acute urinary retention and surgery related to benign prostatic hyperplasia was greater in men with higher baseline symptoms ${ }^{16}$ : the PLESS data showed a relative risk reduction at four years of $57 \%$ and $55 \%$ for acute urinary retention and surgery with finasteride. ${ }^{4}$ While both finasteride and dutasteride decrease prostate size, the higher relative risk reduction seen in our study may be related to the greater reduction in prostate volume seen with dutasteride. ${ }^{814}$ The hazard ratio for progression of benign prostatic hyperplasia in our study is similar to that reported in the secondary analysis of the Prostate Cancer Prevention Trial. ${ }^{15}$ However, that study included starting medications for benign prostatic hyperplasia as part of the composite end point, which may have comprised around 50\% of the composite end points. ${ }^{17}$ The important end points for surgery related to benign prostatic hyperplasia and for urinary retention seem higher in our study, probably because our population is enriched with men with benign prostatic hyperplasia.

In the Medical Therapy of Prostatic Symptoms (MTOPS) study, the NNT with finasteride for men with a prostate size $>40 \mathrm{~mL}$ or prostate specific antigen level $>4 \mathrm{ng} / \mathrm{mL}$ was 7.2 to prevent one patient developing clinical progression of benign prostatic hyperplasia. ${ }^{2}$ While the NNT for our study is similar (6.7), the differences between the studies are noteworthy. Our study has a larger proportion of urinary tract infections and a lower proportion of acute urinary retention compared with the MTOPS study. This is important, as preventing symptoms with medical therapy has less merit than preventing specific complications. Also, it is important to note that incontinence or renal failure was not included as part of our composite end point. Despite, by definition, fewer symptomatic patients in our study cohort (mean IPSS score $4 v 17$ ) and fewer end points, we did find a significant benefit.

\section{Implications of study results}

Treating asymptomatic patients is not an uncommon approach in medicine. Primary prevention with drugs is used to prevent cardiovascular complications and to reduce the risk of cardiac events. While not as lethal, the 10 year cumulative risk of acute urinary retention is estimated to be twice that of stroke or myocardial infarction. ${ }^{18}$ Further, research has found an episode of urinary retention to have a substantial impact on patients' health related quality of life.$^{19}$ Lower urinary tract symptoms affect almost three quarters men in their 60s, and direct costs in the US exceed $\$ 1$ bn a year, excluding outpatient prescription costs. ${ }^{20}$ For men found to have a large prostate gland during routine rectal examination or imaging, this information may be used to select those for whom preventive medication may improve their quality of life and also yield economic benefits.

The trade-offs to the patient in this scenario are the side effects and cost of treatment. Side effects (table $3 \Downarrow$ ) include erectile dysfunction, decreased ejaculate volume, decreased libido, and gynaecomastia. ${ }^{8}$ Despite a greater patient preference against sexual side effects among those with mild symptoms, trade-off questionnaires suggest men prefer $5 \alpha$ reductase inhibitors compared with no treatment or $\alpha$ blockers. ${ }^{21}$ The concern over 
risk of high grade prostate cancer remains an issue of controversy, ${ }^{22}$ though the incidence of high grade cancer seems to be lower relative to small prostate glands. ${ }^{23}{ }^{24}$ The current drug costs of dutasteride per patient in the UK are $£ 238$ a year (€281, \$365), with total direct costs estimated at $£ 325$ per year. ${ }^{25}$ A recent cost effectiveness study suggested that lifelong monotherapy with dutasteride in unselected patients has a cost per QALY gained of $€ 7274 .{ }^{25}$ Our data suggest that its preventive use in asymptomatic men with enlarged prostates would have a lower cost per QALY, given the similar relative risk reduction used in this cost analysis and the significantly higher incidence of complications related to benign prostatic hyperplasia in our study population. By comparison, the estimated cost of transurethral resection of the prostate (TURP) in the NHS was $£ 2080$, and the estimated cost of one admission for acute urinary retention was $£ 1040 .{ }^{26}$ However, cost effectiveness research to assess the use of dutasteride as a preventive agent in this population is unlikely to occur given that its patent expires in 2013. While some patients will not generally be receptive to preventive drug treatment, the magnitude of risk reduction seen in our study warrants further study of patient preferences for choosing optimal management. Certainly, the potential relative harms to each patient need to be discussed and weighed against the expected potential benefits.

\section{Conclusions}

This study is the first to explore the benefit of treating asymptomatic or mildly symptomatic men with enlarged prostates. In this cohort, dutasteride significantly decreased the incidence of clinical progression of benign prostatic hyperplasia over four years, with a relative risk reduction of over $50 \%$ and an acceptable side effect profile. This post-hoc analysis generates questions on whether $5 \alpha$-reductase inhibitors should be discussed as preventive treatment for patients with an enlarged prostate.

We thank Lauren Marmor and colleagues at GlaxoSmithKline for their permission to use the data from the Reduction by Dutasteride of Prostate Cancer Events (REDUCE) study (Clinical Trials No NCT00056407). We also thank Karen Chadwick at University Health Network, University of Toronto, in facilitating this.

Contributors: PT, DM, and NF initiated the study and designed the statistical analysis plan. PT and DM analysed the data and drafted the paper. GK, AF, AZ, and NF gave critical input on the analysis and revised the paper. PT and NF are the guarantors for the study.

Funding: Permission to use data from the was obtained from GlaxoSmithKline, but no funding of any kind was obtained for this study. Competing interests: All authors have completed the ICMJE uniform disclosure form at www.icmje.org/coi_disclosure.pdf (available on request from the corresponding author) and declare: no support from any organisation for the submitted work; $\mathrm{AF}, \mathrm{NF}$, and $\mathrm{AZ}$ have received research grants and honorariums from GlaxoSmithKline; NF and AF do consultancy for GlaxoSmithKline and Merck; no other relationships or activities that could appear to have influenced the submitted work.

Ethical approval: Not needed. The original protocol was approved by the institutional review board at each research site, and all participants provided written informed consent.

Data sharing: No additional data available.
1 Jacobsen SJ, Jacobson DJ, Girman CJ, Roberts RO, Rhodes T, Guess HA, et al. Treatment for benign prostatic hyperplasia among community dwelling men: the Olmsted County study of urinary symptoms and health status. J Urol 1999;162:1301-6.

2 McConnell JD, Roehrborn CG, Bautista OM, Andriole GL Jr, Dixon CM, Kusek JW, et al. The long-term effect of doxazosin, finasteride, and combination therapy on the clinical progression of benign prostatic hyperplasia. N Engl J Med 2003;349:2387-98.

3 Roehrborn CG, Siami P, Barkin J, Damião R, Major-Walker K, Nandy I, et al. The effects of combination therapy with dutasteride and tamsulosin on clinical outcomes in men with symptomatic benign prostatic hyperplasia: 4 -year results from the CombAT study. Eur Urol 2010;57:123-31.

4 McConnell JD, Bruskewitz R, Walsh P, Andriole G, Lieber M, Holtgrewe HL, et al. The effect of finasteride on the risk of acute urinary retention and the need for surgical treatment among men with benign prostatic hyperplasia. Finasteride Long-Term Efficacy and Safety Study Group. N Engl J Med 1998;338:557-63.

5 Siami P, Roehrborn CG, Barkin J, Damiao R, Wyczolkowski M, Duggan A, et al. Combination therapy with dutasteride and tamsulosin in men with moderate-to-severe benign prostatic hyperplasia and prostate enlargement: the CombAT (Combination of Avodart and Tamsulosin) trial rationale and study design. Contemp Clin Trials 2007;28:770-9.

6 Boyle P, Gould AL, Roehrborn CG. Prostate volume predicts outcome of treatment of benign prostatic hyperplasia with finasteride: meta-analysis of randomized clinical trials. Urology 1996;48:398-405.

7 Oelke M, Bachmann A, Descazeaud A, Emberton M, Gravas S, Michel M, et al. Guidelines on the management of male lower urinary tract symptoms (LUTS), incl. benign prostatic obstruction (BPO). European Association of Urology, 2012. www.uroweb.org/gls/pdf/12 Male_LUTS_LR.pdf

8 Andriole GL, Bostwick DG, Brawley OW, Gomella LG, Marberger M, Montorsi F, et al. Effect of dutasteride on the risk of prostate cancer. N Engl J Med 2010;362:1192-202.

9 Roehrborn CG, Nickel JC, Andriole GL, Gagnier RP, Black L, Wilson TH, et al. Dutasteride improves outcomes of benign prostatic hyperplasia when evaluated for prostate cancer risk reduction: secondary analysis of the REduction by DUtasteride of prostate Cancer Events (REDUCE) trial. Urology 2011;78:641-6.

10 Tacklind J, Fink HA, Macdonald R, Rutks I, Wilt TJ. Finasteride for benign prostatic hyperplasia. Cochrane Database Syst Rev 2010;(10):CD006015.

11 Barry MJ, Williford WO, Chang Y, Machi M, Jones KM, Walker-Corkery E, et al. Benign prostatic hyperplasia specific health status measures in clinical research: how much change in the American Urological Association symptom index and the benign prostatic hyperplasia impact index is perceptible to patients? J Urol 1995:154:1770-4.

12 Barry MJ, Cantor A, Roehrborn CG. Relationships between participants' international prostate symptom score and BPH impact index changes and global ratings of change in a trial of phytotherapy for men with lower urinary tract symptoms. J Urol 2012, doi:10. 1016/j.juro.2012.08.257.

13 Bartsch G, Fitzpatrick JM, Schalken JA, Isaacs J, Nordling J, Roehrborn CG. Consensus statement: the role of prostate-specific antigen in managing the patient with benign prostatic hyperplasia. BJU Int 2004:93(suppl 1):27-9.

14 Thompson IM, Goodman PJ, Tangen CM, Lucia MS, Miller GJ, Ford LG, et al. The influence of finasteride on the development of prostate cancer. N Engl J Med 2003;349:215-24.

15 Parsons JK, Schenk JM, Arnold KB, Messer K, Till C, Thompson IM, et al. Finasteride reduces the risk of incident clinical benign prostatic hyperplasia. Eur Urol 2012;62:234-41.

16 Kaplan S, Garvin D, Gilhooly P, Koppel M, Labasky R, Milsten R, et al. Impact of baseline symptom severity on future risk of benign prostatic hyperplasia-related outcomes and long-term response to finasteride. Urology 2000;56:610-6.

17 Hamilton RJ, Andriole GL, Freedland SJ. 5a-reductase inhibitors: preventing the treatable. Eur Urol 2012;62:242-4; discussion 244-5.

18 Jacobsen SJ, Jacobson DJ, Girman CJ, Roberts RO, Rhodes T, Guess HA, et al. Natural history of prostatism: risk factors for acute urinary retention. J Urol 1997;158:481-7.

19 Thomas K, Oades G, Taylor-Hay C, Kirby RS. Acute urinary retention: what is the impact on patients' quality of life? BJU Int 2005;95:72-6.

20 Wei JT, Calhoun E, Jacobsen SJ. Urologic diseases in America project: benign prostatic hyperplasia. J Urol 2008;179:S75-80.

21 Watson V, Ryan M, Brown CT, Barnett G, Ellis BW, Emberton M. Eliciting preferences for drug treatment of lower urinary tract symptoms associated with benign prostatic hyperplasia. J Urol 2004;172:2321-5.

22 Theoret MR, Ning Y-M, Zhang JJ, Justice R, Keegan P, Pazdur R. The risks and benefits of 5a-reductase inhibitors for prostate-cancer prevention. N Engl J Med 2011;365:97-9.

23 Freedland SJ, Isaacs WB, Platz EA, Terris MK, Aronson WJ, Amling CL, et al. Prostate size and risk of high-grade, advanced prostate cancer and biochemical progression after radical prostatectomy: a search database study. J Clin Oncol 2005;23:7546-54.

24 Briganti A, Chun FK-H, Suardi N, Gallina A, Walz J, Graefen M, et al. Prostate volume and adverse prostate cancer features: fact not artifact. Eur J Cancer 2007;43:2669-77.

25 Bjerklund Johansen TE, Baker TM, Black LK. Cost-effectiveness of combination therapy for treatment of benign prostatic hyperplasia: a model based on the findings of the Combination of Avodart and Tamsulosin trial. BJU Int 2012;109:731-8.

26 Kirby RS, Kirby M, Fitzpatrick JM. Benign prostatic hyperplasia: counting the cost of its management. BJU Int 2010;105:901-2.

\section{Accepted: 20 March 2013}

\section{Cite this as: BMJ 2013;346:f2109}

This is an Open Access article distributed in accordance with the Creative Commons Attribution Non Commercial (CC BY-NC 3.0) license, which permits others to distribute, remix, adapt, build upon this work non-commercially, and license their derivative works on different terms, provided the original work is properly cited and the use is non-commercial. See: http://creativecommons.org/licenses/by-nc/3.0/. 


\section{What is already known on this topic}

Dutasteride, a 5 a reductase inhibitor, is an established treatment for lower urinary tract symptoms due to benign prostatic hyperplasia, particularly among men with an enlarged prostate

Men with an enlarged prostate are at risk of urinary symptoms and complications such as acute urinary retention, urinary tract infections, and need for surgery.

However, none of the major trials of 5 a reductase inhibitors have included asymptomatic or minimally symptomatic men

\section{What this study adds}

This post hoc analysis of trial data uniquely estimates the benefit of dutasteride among men with no or minimal symptoms at risk of complications from benign prostatic hyperplasia due to prostate enlargement

Dutasteride significantly decreased the incidence of clinical progression of benign prostatic hyperplasia over four years, with a relative risk reduction of over $50 \%$ and an acceptable side effect profile

\section{Tables}

\begin{tabular}{|c|c|c|}
\hline Characteristic & Placebo $(n=825)$ & Dutasteride $(n=792)$ \\
\hline Age (years) & $64(59-68)$ & $63(58-67)$ \\
\hline No (\%) of white ethnicity & $760(92)$ & $738(93)$ \\
\hline Prostate volume $\left(\mathrm{cm}^{3}\right)$ & $51.9(45.2-60.3)$ & $52.0(45.5-61.9)$ \\
\hline Serum PSA concentration (ng/mL) & $6.0(4.6-7.5)$ & $5.9(4.5-7.5)$ \\
\hline Maximum urinary flow rate (mL/sec) & $13(9.7-18)$ & $13(10-17.6)$ \\
\hline Post-void residual urine volume $(\mathrm{mL})$ & $28(2-70)$ & $30(6-73)$ \\
\hline No (\%) who were sexually active & $702(85 \%)$ & $663(83 \%)$ \\
\hline IPSS score & $4.0(3-6)$ & $4(3-6)$ \\
\hline
\end{tabular}

PSA=prostate specific antigen. IPSS=International Prostate Symptom Score. 
Table 2| Clinical progression of benign prostatic hyperplasia at four years among 1617 asymptomatic men with enlarged prostate glands who were randomised to treatment with dutasteride or placebo

No (\%) of patients

\begin{tabular}{lccccc}
\cline { 2 - 5 } Clinical event & Total & Placebo $(\mathbf{n = 8 2 5})$ & Dutasteride $(\mathbf{n = 7 9 2 )}$ & Odds ratio (95\% $\mathbf{~ C l})^{*}$ & P value \\
Acute urinary retention & $76(4.7)$ & $63(7.6)$ & $13(1.6)$ & $0.20(0.11$ to 0.37$)$ & $<0.001$ \\
\hline BPH-related surgery & $46(2.8)$ & $39(4.7)$ & $7(0.9)$ & $0.18(0.08$ to 0.40$)$ & $<0.001$ \\
\hline Urinary tract infection & $141(9.7)$ & $87(10.5)$ & $54(6.8)$ & $0.62(0.43$ to 0.88$)$ & 0.008 \\
\hline IPSS score increase of $\geq 4$ points & $306(18.9)$ & $192(23.3)$ & $114(14.4)$ & $0.55(0.40$ to 0.72$)$ & $<0.001$ \\
\hline
\end{tabular}

$\mathrm{BPH}=$ benign prostatic hyperplasia. IPSS=International Prostate Symptom Score

${ }^{*}$ Odds ratio from logistic regression analysis. 
Table 3| Incidence of drug related adverse events among 1617 asymptomatic men with enlarged prostate glands who were randomised to treatment with dutasteride or placebo

No (\%) of patients

Drug related adverse event* Placebo $(n=825)$ Dutasteride $(n=792) \quad$ Absolute risk $(95 \%$ Cl) P value

\begin{tabular}{lcccc} 
Any & $134(16.2)$ & $276(34.8)$ & $18.6(14.4$ to 22.7) & $<0.001$ \\
\hline Decreased libido & $10(1.2)$ & $35(4.4)$ & $3.2(1.6$ to 9.8$)$ & $<0.001$ \\
\hline Loss of libido & $9(1.1)$ & $19(2.4)$ & $1.3(0.03$ to 2.6) & 0.04 \\
\hline Erectile dysfunction & $42(5.1)$ & $71(9.0)$ & $3.9(1.4$ to 6.4$)$ & 0.02 \\
\hline Gynaecomastia & $6(0.7)$ & $19(2.4)$ & $1.7(0.5$ to 2.9$)$ & 0.006 \\
\hline Decreased semen volume & $1(0.1)$ & $12(1.5)$ & $1.4(0.5$ to 2.3$)$ & 0.002 \\
\hline
\end{tabular}

*All adverse events reported to occur in $>1 \%$ of subjects in either group. 
Table 4| Number needed to treat (NNT) for composite and individual end points from study of asymptomatic men with enlarged prostate glands treated with dutasteride or placebo

\begin{tabular}{|c|c|}
\hline Event to be prevented & NNT $(95 \% \mathrm{Cl})$ \\
\hline Composite end point ${ }^{*}$ & $6(5$ to 9$)$ \\
\hline IPSS score increase of $\geq 4$ points (urination globally "worse"1112) & $11(8$ to 20$)$ \\
\hline Acute urinary retention & 16 (12 to 25$)$ \\
\hline BPH-related surgery & 26 (18 to 44$)$ \\
\hline Acute urinary retention or $\mathrm{BPH}$-related surgery & $13(10$ to 18$)$ \\
\hline Urinary tract infection & 26 (15 to 102$)$ \\
\hline
\end{tabular}

$\mathrm{BPH}=$ benign prostatic hyperplasia. IPSS=International Prostate Symptom Score

${ }^{*}$ Composite end point=acute urinary retention, IPSS score increase of $\geq 4$ points, BPH-related surgery, or urinary tract infection. 


\section{Figures}

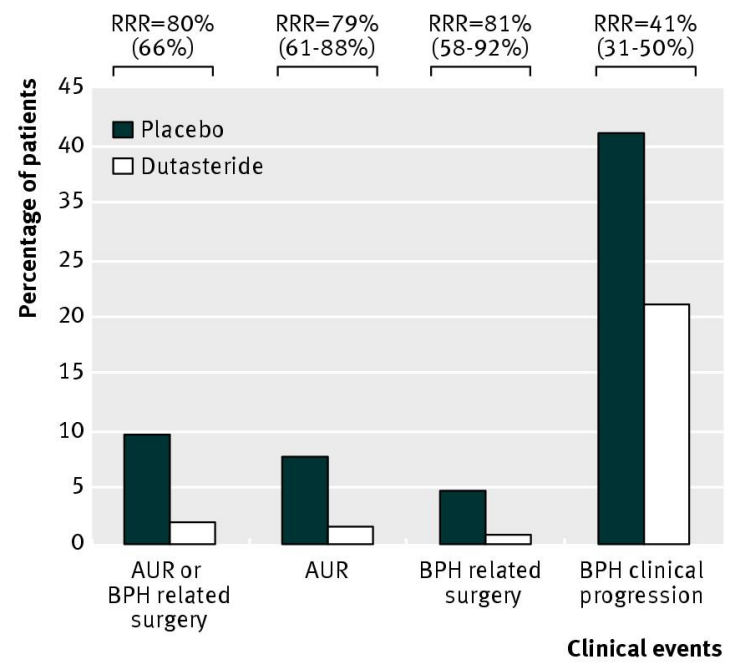

AUR=acute urinary retention. $\mathrm{BPH}=$ benign prostatic hyperplasia.

RRR=relative risk reduction.

Fig 1 Absolute rates and relative risk reduction for acute urinary retention, surgery related to benign prostatic hyperplasia, and clinical progression of benign prostatic hyperplasia among 1617 asymptomatic men with enlarged prostate glands who were randomised to treatment with dutasteride or placebo

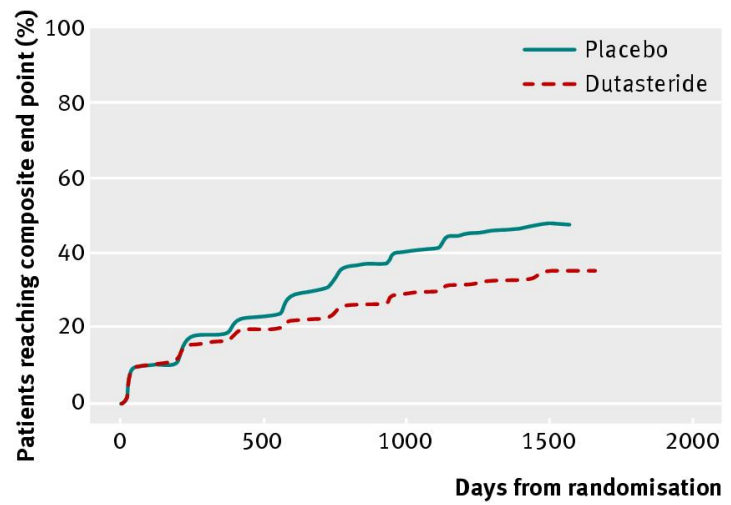

Fig 2 Time to first event indicating progression of benign prostatic hyperplasia among 1617 asymptomatic men with enlarged prostate glands who were randomised to treatment with dutasteride or placebo 